\title{
The INFLUENCES OF CUTTING Edge RAdiUS ON SURFACE ROUGHNeSS WHEN MiLling NiCKel Alloy
}

\author{
Ondřej Hronek \& Miroslav Zetek
}
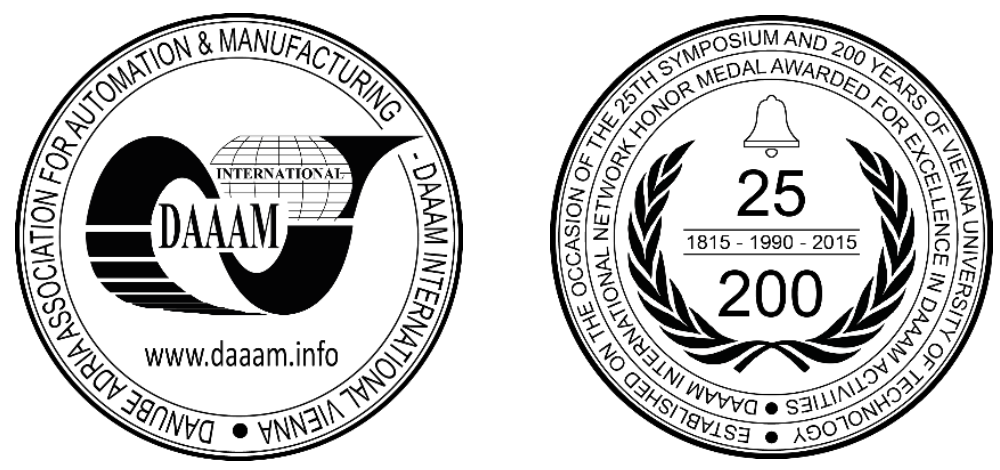

This Publication has to be referred as: Hronek, O[ndrej] \& Zetek, M[iroslav] (2017). The Influences of Cutting Edge Radius on Surface Roughness when Milling Nickel Alloy, Proceedings of the 28th DAAAM International Symposium, pp.1037-1043, B. Katalinic (Ed.), Published by DAAAM International, ISBN 978-3-902734-11-2, ISSN 1726-9679, Vienna, Austria

DOI: $10.2507 / 28$ th.daaam.proceedings.144

\begin{abstract}
Currently one of the most important tasks of industrial enterprises is fulfilling the required quality of the products. This article is focused just on surface roughness, because product quality is an extensive concept. To obtain the desired product shape and dimensions, a cutting tool must remove the necessary volume of chips. The cutting tool and process conditions also affect the surface roughness during the machining process. The effect of the cutting edge radius on the roughness is studied during the experiment. The cutting tools have modified microgeometries. There are six cutting tools with cutting edge radii of $15 \mu \mathrm{m} ; 20 \mu \mathrm{m}$ and $25 \mu \mathrm{m}$. The roughness measurement was performed using the non-contact method on an IGM G4.
\end{abstract}

Keywords: Cutting edge modification; Drag finishing; Immersion depth; Cutting tool microgeometry

\section{Introduction}

The nickel alloy Inconel 718 is often used for extremely heavy-duty products. Its properties such as excellent mechanical properties, heat resistance and toughness are the main reasons why it is used for products that are thermally and mechanically stressed. However, because of its high heat resistance, the abrasive effects of the chemical composition of the alloy and the self-hardening ability [1], these alloys are incorporated into the ISO S group, the group of materials which are difficult to machine. These alloys exhibit a high cutting resistance, moreover, there is a high proportion of heat transfer to the cutting tool. This is the reason for the research and development of machining nickel alloys, such as Inconel 718.

When adjusting the cutting tool microgeometry mechanical, or thermal and chemical methods to increase the durability, it is necessary to examine the effect of microgeometry modification on the surface quality. The goal is to modify the cutting edge, so that the cutting tool achieves the required durability. At the same time, the cutting process cannot have excessive vibrations, and the required roughness of the workpiece surface and shape accuracy must be maintained. Because of the frequent use of this material for stressed products, it is important to measure the residual stress on the surface layers. It has been found [2] [8] that machining of materials which are difficult to machine (ISO S) leads to different orientations and sizes of residual stresses depending on the machining environment. 
Therefore, it is necessary to know and examine how the combination of the cutting process and the machining environment affects the residual stresses in the layers on and under the surface.

The final roughness is affected by the machining method, the machined material and its heat treatment, the cutting tool, the cutting conditions, etc. The cutting angles of the cutting tool have one of the biggest influences on the quality of the machined surface. Also the choice of the cutting conditions is also related to this. However, the system of surface quality - the cutting tool - machined material also influences the machining environment. Kumar et al. [3] investigated the influences of the machining environment on the roughness of nickel alloy Inconel 718. It was found that machining without cutting fluid negatively affects the surface roughness compared to the MQL (minimum quantity lubrication) and processing with cutting fluid. Currently, there are other types of machining environment that affect workpiece surface quality. Shokani et al. [4] focus on using MQL, cryogenic cooling and their combinations. In these environment types, the combination of MQL and cryogenic cooling the lowest roughness was achieved $(\mathrm{Ra}=0.3 \mu \mathrm{m}-0.4 \mu \mathrm{m})$.

\subsection{Roughness measurement}

Currently, two methods are used for measuring roughness: contact and non-contact measurement. Both of these methods have their own advantages and disadvantages. The principle of contact measurement consists in the contact of a stylus with the measured surface. The measuring stylus moves over the measured surface at a constant speed. The stylus copies the shape of the surface. The stylus movement is recorded on the measuring software. The results of the roughness measurement are evaluated from this software. [5] This type of measurement has many advantages. It is simpler, quicker, an cheaper than non-contact roughness measurement. However, the disadvantage of contact measurement is the limited capability for measuring stylus on the complex components. In some cases the measured values are distorted. The measuring stylus does not accurately copy the shape of the measured profile of the measured area. Also, the tip of the measuring stylus is worn during measurement. This wear causes errors in the on measurement evaluation. [5] The noncontact method is the second type of roughness measurement. Measuring devices can work on the focus variation principle. In this case, they are the optical scanning microscopes (e.g. IFM G4). Non-contact roughness measurement provides the ability to measure the roughness on complex-shaped surfaces. For example, measuring the roughness on the flank and rake face of a cutting edge. It is also possible to evaluate the roughness of curved surfaces. The software tools for these microscopes allow far greater capabilities for working with the measured data.

\section{Cutting Edge Modification}

Monolithic end mill tools were used for the experiment. Sintered carbide was selected as the cutting material. To confirm or disprove the effect of cutting edge microgeometry on the surface roughness it was necessary to modify the cutting edge microgeometry. After grinding the cutting tools, the microgeometry was measured. An optical/scanning microscope was used for microgeometry measurement (Fig. 1. a)). The microscope is based on the focus variation principle. It is a non-contact microscope, suitable for cutting tools microgeometry measurement. The cutting edge radius ranged from 2 to 3 microns after grinding. Cutting edge modification followed after measurement. A drag finishing machine was used for cutting edge modification (Fig. 2. b)). The theoretical values of the cutting edge radius were selected: $15 \mu \mathrm{m} ; 20 \mu \mathrm{m}$ and $25 \mu \mathrm{m}$. Six tools were used in the experiment, so two end mill tools were selected for each cutting edge modification.
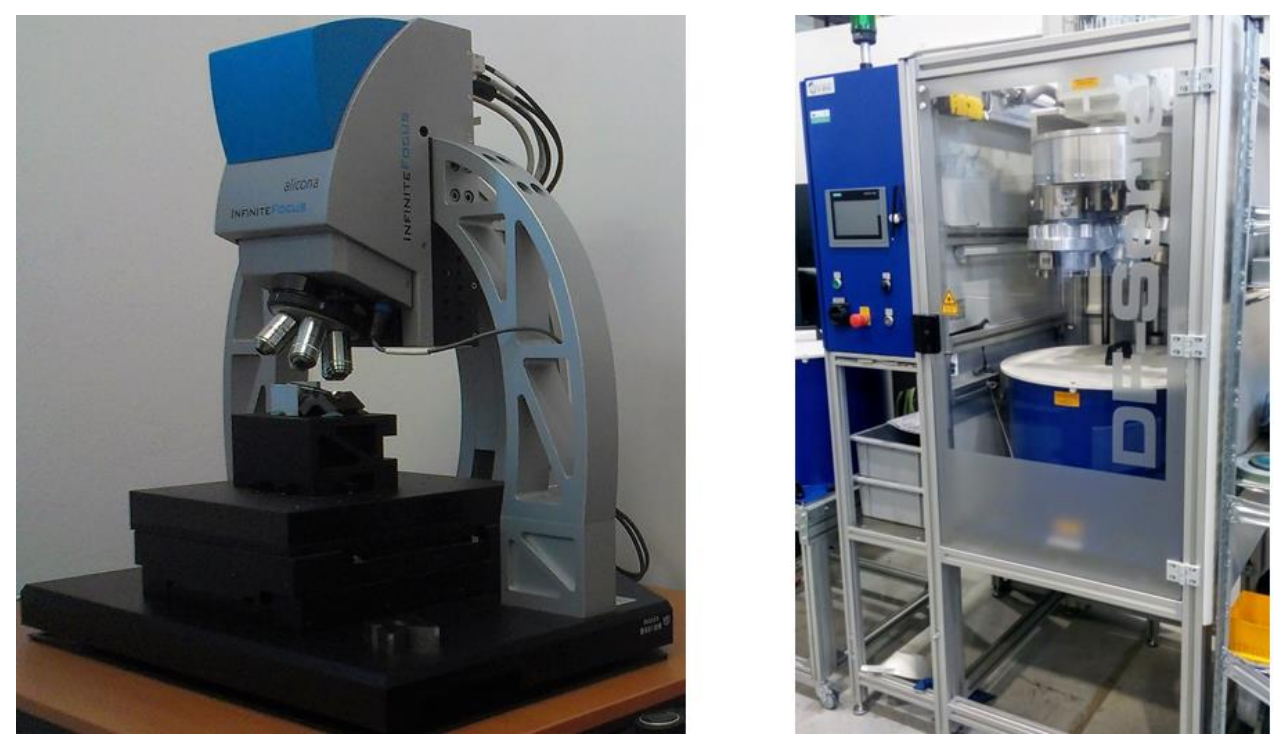

Fig. 1. a) IFM G4, b) Drag finishing machine 
The drag finishing process parameters used to achieve a proper cutting edge radius are shown in Table 1. At the same time, the cutting edge before and after modification is compared using differential analysis software. In each analysis, the influence of different cutting edge radius values is made visible (by a colour spectrum). From these analyses, it can be seen that the cutting edges have no defects on the cutting edge.

After measurement, the coating process followed. Schornik V. [6] confirmed in a practical experiment that the chemical composition and the thickness of the thin layer influences the durability and cutting forces when milling nickel alloy Inconel 718. Therefore, it is important to pay attention to the choice of the proper thin layer for machining Inconel 718. It is necessary to select a thin layer with properties such as: hardness, heat resistance, thin, with a low friction coefficient, etc. A thin layer called Triple Coating Cr was selected for this experiment. The properties of this thin layer are suitable for materials which are difficult to machine.

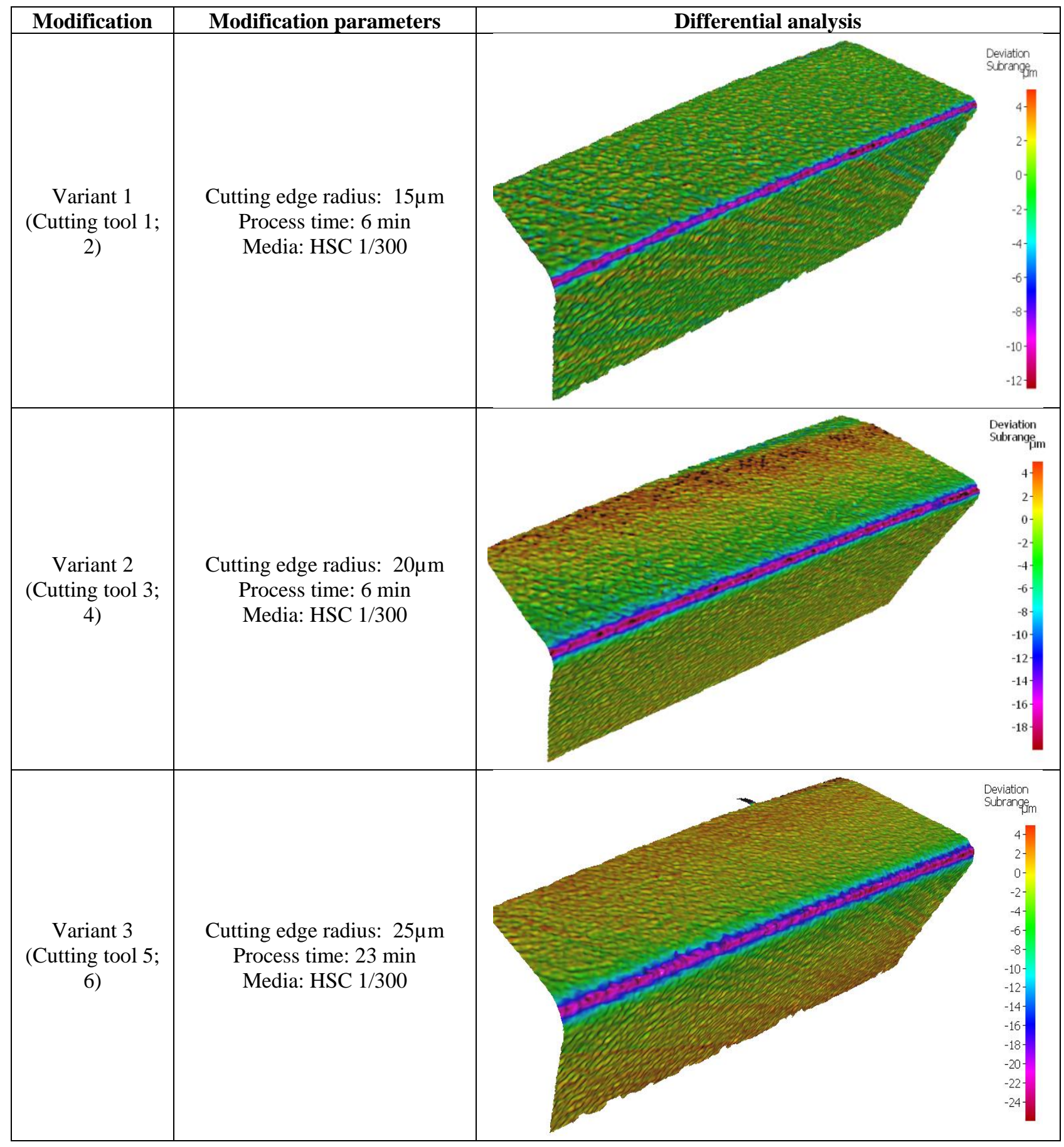

Table 1. Variants of cutting edge modification 


\section{Experiment}

In the first step, the process parameters for milling were selected. The machined material had the biggest influence on the choice of these parameters (see Table. 2). The Inconel 718 has properties such as high temperature strength, selfhardening by plastic deformation, hardness and vulnerability to abrasive tool wear. It is necessary to select appropriate cutting conditions that will increase the cutting tool life and also stabilize the cutting process. [3] [4] [6] Process parameters are also based on experience gained from previous tests of machining Inconel 718. Table 2. Shows the process parameters used. Kroft L. [7] focused on the influence of step-over on the cutting force Fy . In this article it was found that the lower step-over [mm] causes a reduction of force Fy. In the case of milling, the step-over value is equal to $\mathrm{a}_{\mathrm{e}}$ (cutting width). For this experiment, cutting width was $0.5 \mathrm{~mm}$.

\begin{tabular}{|l|l|l|l|l|l|}
\hline $\mathbf{v} \mathbf{c}[\mathbf{m} / \mathbf{m i n}]$ & $\mathbf{f}_{\mathbf{z}}[\mathbf{m m}]$ & $\mathbf{a}_{\mathbf{p}}[\mathbf{m m}]$ & $\mathbf{a e}[\mathbf{m m}]$ & Milling type & $\begin{array}{l}\text { Machining } \\
\text { environment }\end{array}$ \\
\hline 35 & 0.04 & 3 & 0.5 & Down Milling & Cutting fluid \\
\hline
\end{tabular}

Table 2. Process parameters

The MCV 750A three-axis milling centre used for the experiment. Cutting tools were clamped into a polygonal tool holder which is characterized by appropriate stiffness and a solid radial runout. This will make the system Cutting toolHolder more rigid than to the frequently used collet clamp. The workpiece was clamped into a chuck. Each cutting tool has its own workpiece. It was necessary to use six workpieces for surface roughness evaluation. The experiment consisted of several simple steps. Once the cutting tool and workpiece clamped are, the cutting tool makes one cross. After that, the cutting tool and workpiece are replaced by another tool and workpiece. By that simple principle, each of the six cutting tools were tested. As mentioned earlier, the cutting environment also has an impact on the surface roughness during machining. In this case, a process media was used during machining for cooling the cutting process.
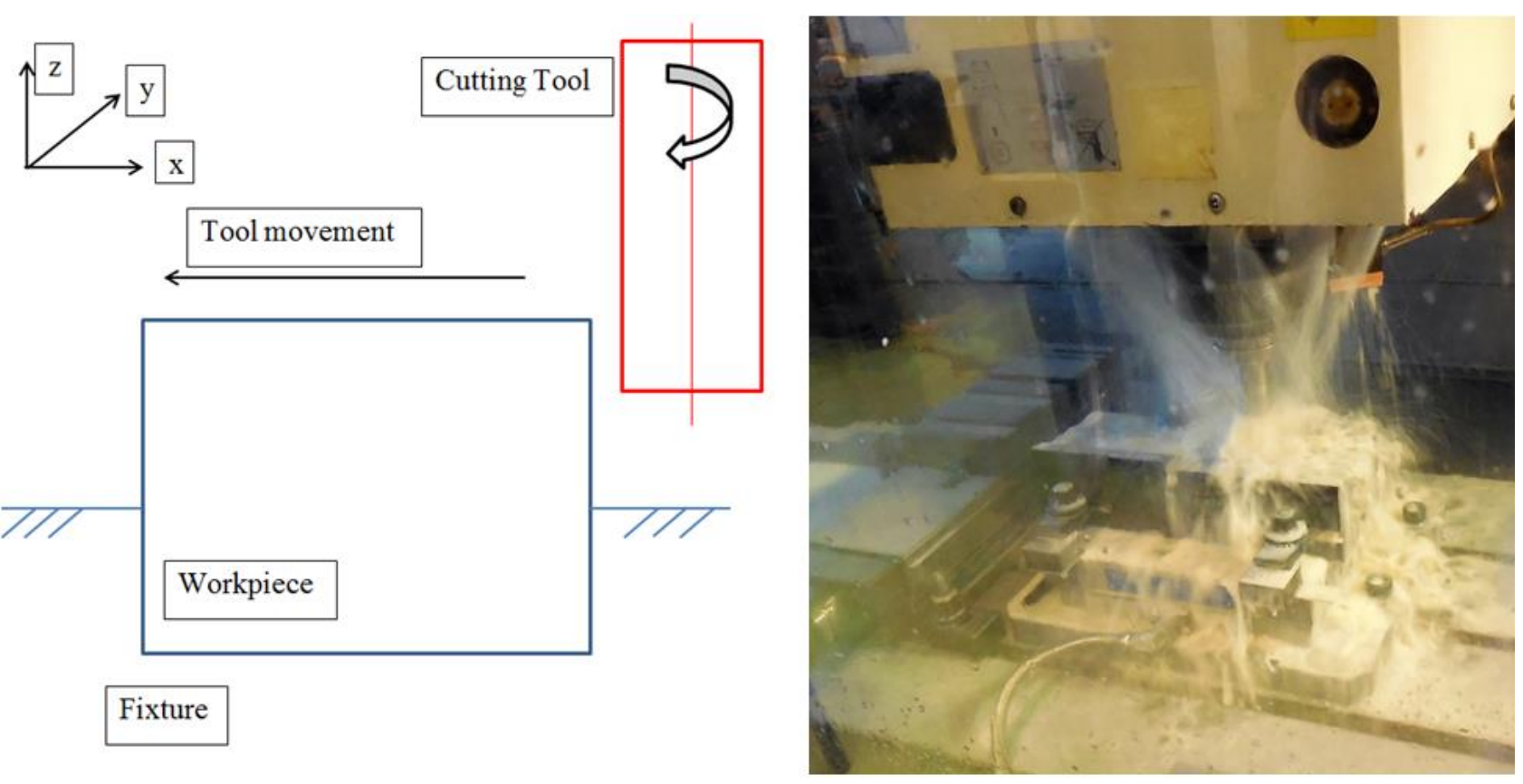

Fig. 2. a) Cutting process diagram, b) Real cutting process

\section{Results and Discussion}

After the experiment was completed, the machined surface was measured. An IFM G4 microscope was used for the roughness measurement. In addition to measuring shape and size, the advantage of this microscope is its ability to measure and evaluate surface roughness. The 50x objective was selected to measure the machined roughness. Also, it is necessary to select suitable lateral and vertical resolution, contrast and lighting settings. These set up parameters remains constant for each of the six workpiece surface measurements. Fig. 3. a) shows the surface on which the roughness was measured and evaluated. This area was created by the cylindrical part of the cutting tool.

The roughness measurement was carried out on an area $1.5 \times 1.5 \mathrm{~mm}$. However, it was not yet possible to measure the surface roughness of the measured surface. An area created by the microscope showed waviness, so it was not possible to measure roughness on this type of surface. Therefore, the next step was to remove the waviness, because the waviness affects the values of the roughness measurement. 
The marks from the cutting tool can be seen on the measured surface (Fig. 3.b)). These marks are visible on all of the workpieces. These marks are created by elastic/plastic deformation, by cutting forces and material properties. During measurement it was found that the distance between the track approximately corresponds to the a feed value $\mathrm{f}_{\mathrm{z}}=0.04 \mathrm{~mm}$.
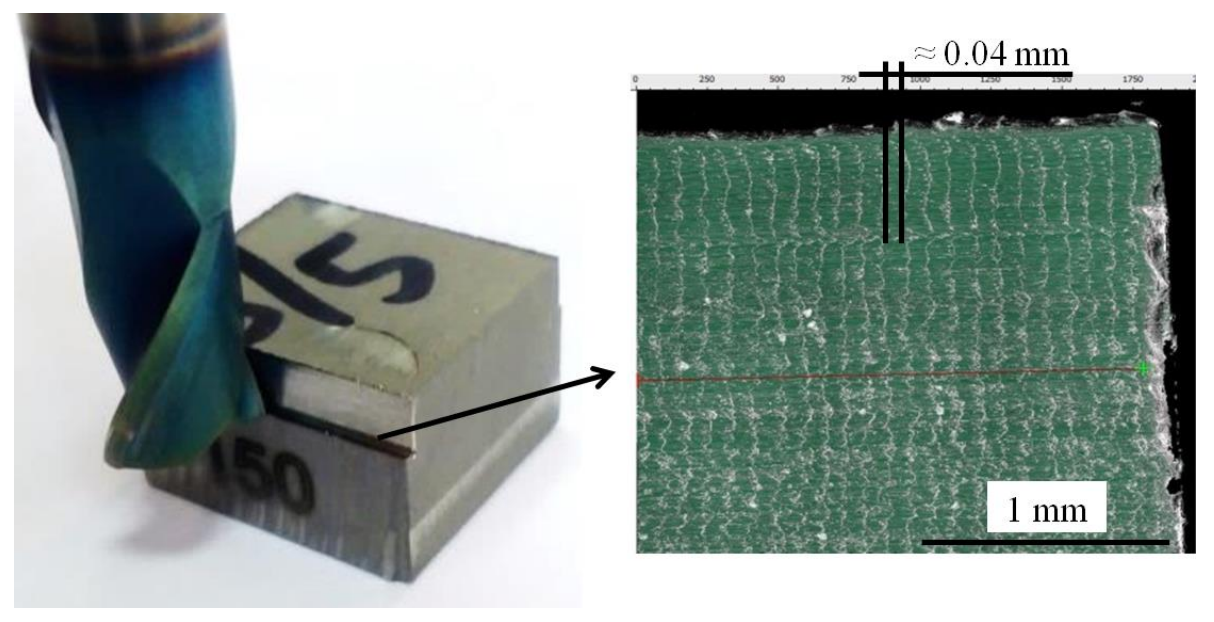

Fig. 3. a) Machined surface, b) Detailed view of the machined surface by IFM G4

Roughness measurement and evaluation is efficiently carried out using an IFM G4 microscope. It is possible to measure linear and surface roughness. The main roughness parameters were selected for evaluation. Two of these three parameters are linear $\mathrm{Ra}$ and $\mathrm{Rz}$ parameters. The last parameter to be evaluated is the surface roughness Sa. Table 3. shows the measured values on the surface created by tool number 1 . The same measurement method was used for each workpiece. The roughness was measured perpendicular to the tracks of the cutting tool. Five measurements were made on each workpiece (Table. 3). The arithmetic mean (x) was calculated from each of these measurements

\begin{tabular}{|c|c|c|}
\hline \multicolumn{3}{|c|}{ Cutting tool 1- roughness parameter Ra measurement } \\
\hline Roughness measurement & $\mathbf{x}_{\mathbf{i}}[\boldsymbol{\mu \mathbf { m }}]$ & $\Delta_{\mathbf{i}}=\mathbf{x}_{\mathbf{i}}-\mathbf{x}[\boldsymbol{\mu m}]$ \\
\hline 1 & 0.278 & -0.0756 \\
\hline 2 & 0.322 & -0.0316 \\
\hline 3 & 0.288 & -0.0656 \\
\hline 4 & 0.490 & 0.1364 \\
\hline 5 & 0.390 & 0.0364 \\
\hline $\mathrm{X}$ & $\mathbf{0 . 3 5 3 6}$ & $\boldsymbol{\Sigma} \Delta_{\mathbf{i}}=\mathbf{0}$ \\
\hline
\end{tabular}

Table 3. Evaluation of measured values

\subsection{Results}

This section deals with the evaluation of the measured values. Fig. 4. Shows the measured roughness values (Ra; Rz; $\mathrm{Sa}$ ) depending on the cutting edge radius. It has been found, that the cutting edge radius affects the roughness of the machined surface during the milling process, with constant process parameters. The lowest linear and surface roughness of the workpiece were made by cutting tools with $r_{n}=15 \mu \mathrm{m}$. Although the cutting edge radius is created on these tools (Variant 1), the cutting edge is still sufficiently sharp for easy chip creation during the machining of Inconel 718. Workpiece properties such as high hardness and toughness negatively affect the workpiece roughness during milling when using cutting tools with $r_{n}=25 \mu \mathrm{m}$. Due to the higher cutting edge radius, there is an energetically more complex process of chip formation. In addition, higher $r_{n}$ negatively affects plastic deformation and the final surface roughness.

The roughness parameter Ra ranges from $0.343 \mu \mathrm{m}$ to $0.688 \mu \mathrm{m}$. It is possible to say that all of the tested cutting tools with different microgeometries have created high quality workpiece surfaces. However, modern quality evaluation uses more roughness parameters for the evaluation of surface roughness, and the results are more credible and also the conclusions are more accurate. Another evaluated parameter was the largest profile height (Rz). Even in this case, the highest roughness values of Rz were obtained with Variant 3, $\mathrm{r}_{\mathrm{n}}=25 \mu \mathrm{m}$. Cutting tools with cutting edges of $15 \mu \mathrm{m}$ and $20 \mu \mathrm{m}$ have similar roughness Rz. But compared to the tool with $r_{n}=25 \mu \mathrm{m}$, there is a significant difference in the surface roughness evaluated by parameter Rz. This is related to the fact that a cutting tool with a higher cutting edge uses higher energy when cutting the chip during the milling process. Also, this energy can cause increased vibration and cutting forces. These effects lead to a deterioration of the surface roughness. 
The last and final measured parameter was the arithmetical mean height Sa. This is an extension of the Ra parameter on the surface area. The result of the evaluation of roughness Sa give us the same dependence as the Ra evaluation. So, cutting tools with lower cutting edge radius improve the workpiece surface. The surface roughness Sa ranges from 0.522 $\mu \mathrm{m}$ to $0.787 \mu \mathrm{m}$.

It is necessary to realize that many parameters influence non-contact measurement. These parameters could negatively affect the final measured values. Parameters which could affect the measurements are: objective selection, lateral and vertical distinction, contrast, brightness, waviness removal, etc.

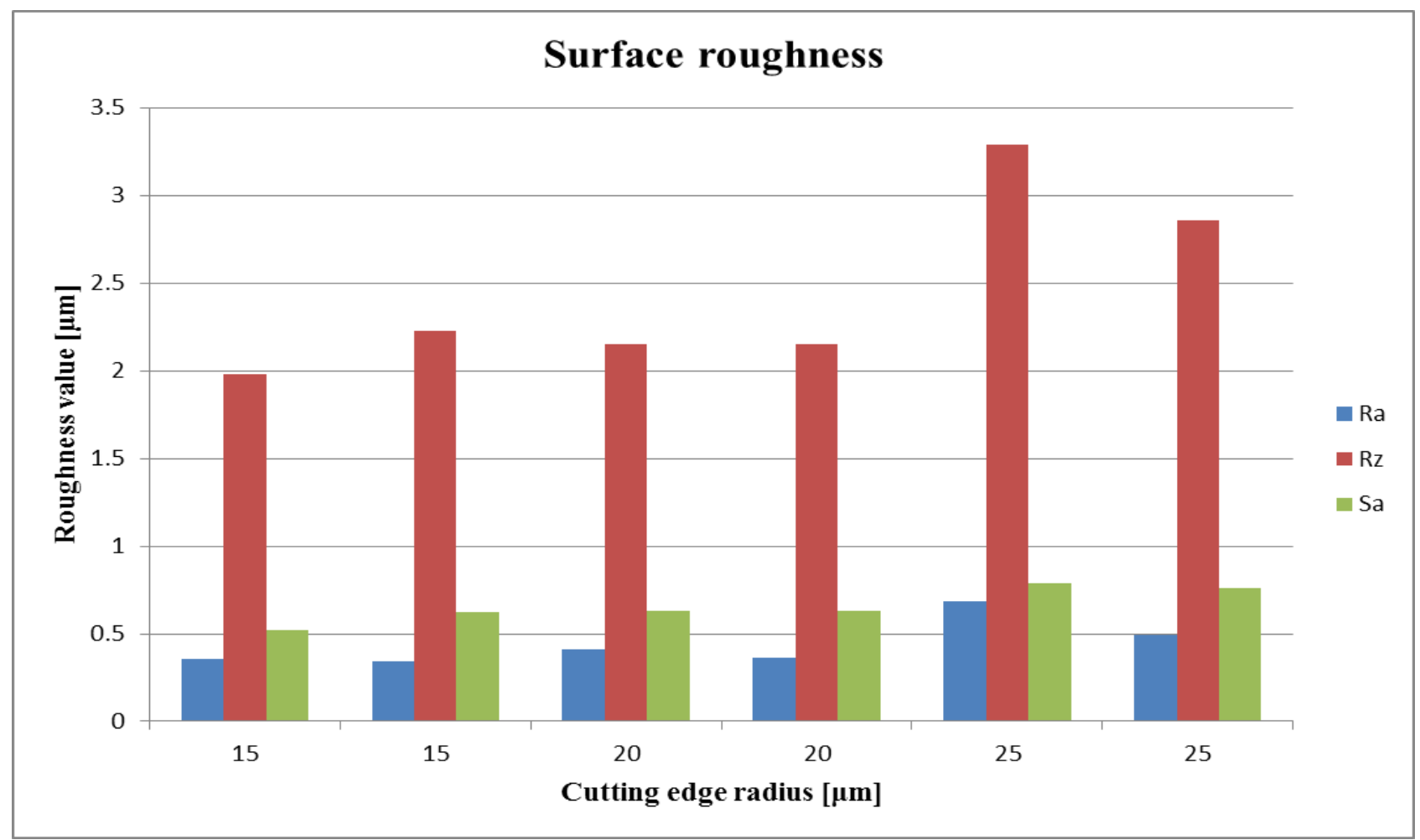

Fig. 4. Influences of $r_{n}$ on workpiece roughness

\section{Conclusion}

This article deals with the influences of the cutting edge radius on the workpiece surface roughness. Three variants of cutting edge radius $(15 \mu \mathrm{m} ; 20 \mu \mathrm{m}$ and $25 \mu \mathrm{m})$ were tested during the experiment. Process parameters were constant during the milling process. Nickel alloy Inconel 718 was the machined material.

The experiment shows the dependence between the cutting tool radius and the roughness of the workpiece. After the practical part and evaluation, the following conclusions were reached:

a) Higher cutting edge radius causes an increase of roughness parameters $\mathrm{Ra} ; \mathrm{Rz} ; \mathrm{Sa}$

b) The largest difference in Ra parameter was between the cutting tools of Variant 1 and Variant 3. The cutting tool with a cutting edge radius of $15 \mu \mathrm{m}$ had a roughness $\mathrm{Ra}=0.343 \mu \mathrm{m}$ while the cutting tool with $\mathrm{r}_{\mathrm{n}}=25 \mu \mathrm{m}$ had a roughness of $\mathrm{Ra}=0.688 \mu \mathrm{m}$.

c) The largest profile height $\mathrm{Rz}$ was the second roughness parameter that was evaluated. In this case, the same influence between the cutting edge radius and workpiece roughness was detected. This parameter revealed greater differences between the highest profile height. The cutting tool with $\mathrm{r}_{\mathrm{n}}=15 \mu \mathrm{m}$ had a roughness of $\mathrm{Rz}=1.982 \mu \mathrm{m}$, while the cutting tool with $r_{n}=25 \mu \mathrm{m}$ had a much higher roughness; $R z=3.292 \mu \mathrm{m}$.

d) The surface roughness parameter Sa was also used for evaluation. The dependence between the cutting edge radius and the workpiece roughness was equal to the parameters $\mathrm{Ra}$ and $\mathrm{Rz}$.

It is important to say that the impact of the cutting tool on the surface quality cannot be considered separately. Therefore, even in this experiment, it is necessary to realize that the machine, the cutting tool, the workpiece, and the workpiece holder influence the roughness and geometrical accuracy.

In the future, the influences of the microgeometry on surface quality will be investigated further. The aim of these experiments is to increase the quality of the workpiece surface. Moreover, these experiments will find the relationships between cutting tool microgeometry, process parameters, the machined material and the surface roughness. The aim is also to increase the quality of cutting tools. 


\section{Acknowledgments}

The present contribution has been prepared under project LO1502 'Development of the Regional Technological Institute' under the auspices of the National Sustainability Programme I of the Ministry of Education of the Czech Republic aimed at supporting research, experimental development and innovation.

\section{References}

[1] Lopéz de lacalle, L. N., Peréz, J., Llorente, J. I., Sánchez, J. A. (2000). Advanced cutting conditions for the milling of aeronautical alloys, Journal of Materials Processing Technology, Vol. 100, 2000, pp. 1 - 11, ISSN: 0924-0136

[2] Malý, J., Zeman, P. \& Mádl. J. (2009). Effect of Cutting Media and Cutting Conditions on Temperature and Residual Stress of Machined Surface at Milling of Difficult-to-cut Alloy Ti6A14V, [online]. Available from: https://otik.uk.zcu.cz/xmlui/bitstream/handle/11025/16437/Maly.pdf?sequence=1\&isAllowed=y, [Accessed: 201710-16]

[3] Kumar, S., Singh, D. \& Nirmal, S. K. (2017). Experimental Investigations of Surface Roughness of Inconel 718 under different Machining Conditions, Materials today: PROCEEDING, Vol. 4, 2017, pp. 1179 - 1185, ISSN: 22147853

[4] Shokrani, A., Dhokia, V. \& Newman, S. T. (2017). Hybrid Cooling and Lubricating Technology for CNC Milling of Inconel 718 Nickel Alloy. Procedia Manufacturing. Vol. 11, 2017, pp. 625 - 632, ISSN: 2351-9789

[5] Stout., K. J. \& et al. (2004). Development of Method for the Characterisation of Roughness in Three Dimensions, Penton Press and contributors 2000, ISBN 1-8571-8023-2, London N1 9JN, UK

[6] Schornik, V., Zetek, M. \& Baksa, T. (2016). Durability of the Cutting Tool with Different Thin Layers when Inconel 718 is Machined, Proccedings of the 27th DAAAM International Symposium, pp. 0678 - 0682, B. Katalinic (Ed.), Published by DAAAM International, ISBN 978-3-902734-08-2, ISSN 1726-9679, Vienna, Austria

[7] Kroft, L. (2016). The Influence of the Finishing Strategy on the Quality of the Surface, Proccedings of the 27th DAAAM International Symposium, pp. 0524 - 0533, B. Katalinic (Ed.), Published by DAAAM International, ISBN 978-3-902734-08-2, ISSN 1726-9679, Vienna, Austria

[8] Wang, J., Zhang, D., Wu, B., Luo, M. (2017). Numerical and Empirical Modelling of Machining-induced Residual Stresses in Ball end Milling of Inconel 718. Procedia CIRP. Vol. 58, 2017, pp. 7 - 12, ISSN: 2212-8271 